\title{
A Mesoscale Finite Element Modelling Approach for Understanding Brain Morphology and Material Heterogeneity Effects in Chronic Traumatic Encephalopathy
}

Authors:

A. Bakhtairydavijani ${ }^{\mathrm{a}}$, G. Khalid ${ }^{\mathrm{b}}$, M.A. Murphy ${ }^{\mathrm{a}}$, K.L. Johnson ${ }^{\mathrm{c}}$, L. E. Peterson ${ }^{\mathrm{a}}$, M. Jones ${ }^{\mathrm{d}}$, M.F. Horstemeyer ${ }^{\mathrm{e}}$, A.C. Dobbins ${ }^{\mathrm{f}}$, R. K. Prabhu ${ }^{\mathrm{b}, \mathrm{g}^{*}}$

${ }^{a}$ Center for Advanced Vehicular Systems, Mississippi State University, Starkville, MS, USA;

${ }^{b}$ Middle Technical University, Baghdad, Iraq; ' Sandia National Labs, Albuquerque, NM, USA; ${ }^{d}$ Institute of Medical Engineering \& Medical Physics, Cardiff University, Cardiff, Wales, UK; ${ }^{e}$ Liberty University, Lynchburg, Va, USA; ${ }^{f}$ Department of Biomedical Engineering, University of Alabama at Birmingham, Birmingham, USA; ${ }^{g}$ Department of Agricultural and Biological Engineering, Mississippi State University, Miss. State, USA;

*Corresponding Author: Assistant Professor, Department of Agricultural and Biological Engineering, 130 Creelman St, Mississippi State University, MS 39762.rprabhu@msstate.edu 


\begin{abstract}
(100 words)
Chronic Traumatic Encephalopathy (CTE) affects a significant portion of athletes in contact sports but is difficult to quantify using clinical examinations and modelling approaches. We use an in silico approach to quantify CTE biomechanics using mesoscale Finite Element (FE) analysis that bridges with macroscale whole head FE analysis. The sulci geometry produces complex stress waves that interact with each another to create increased shear stresses at the sulci depth that are significantly larger than in analyses without sulci (from $0.5 \mathrm{kPa}$ to $18.0 \mathrm{kPa}$ ). Also, Peak sulci stresses are located where CTE has been experimentally observed in the literature.
\end{abstract}

Keywords: Mesoscale modelling, finite element analysis, multiscale modelling, chronic traumatic encephalopathy, sulci, traumatic brain injury, American football.

Highlights: 3 to 5 bullet points 85 characters max

- Sulci introduce stress localizations at their depth in the gray matter

- Sulci stress fields interact to produce stress concentration sites in white matter

- Differentiating brain tissue properties did not significantly affect peak stresses 


\section{Introduction}

Chronic Traumatic Encephalopathy (CTE) is a progressive neurodegenerative disease common to a range of contact sports (Bailes et al. 2013). Parker (Parker 1934) first documented CTE, also known as punch drunk syndrome or dementia pugilistica, in boxers. This neurodegeneration has since been identified in multiple sports, including boxing (Saing et al. 2012), wrestling (Cajigal 2007), soccer (Geddes et al. 1999), and American professional football (Omalu et al. 2005). More recently, a post-mortem study of National Football League (NFL) players found 110 out of 111 of the brains examined suffered from CTE (Mez et al. 2017). Considering the progressive nature of this disease, and the lack of sufficient protection through protective gear and guidelines, further study of this disease and its underlying causes can help identify preventive measures and thus benefit the quality of life of these individuals.

Significant evidence points to the relationship between multiple sub-concussions to mild Traumatic Brain Injury (mTBI) and chronic neurological injury. American football players are estimated to experience 100 to 1000 head impacts in a season (Bailes et al. 2013) where more than three concussions correlate with an increased probability of mild cognitive impairment and depression (Guskiewicz et al. 2007). At the same time, it results in a greater probability of future concussions with longer recovery times (McCrea et al. 2003). The CTE pathology includes deposits of tau protein in the form of NeuroFibrillary Tangles (NFTs) and astrocytic tangles, preferentially distributed in superficial layers (Layer II and upper third of layer III) in neocortical areas (Hof et al. 1991); amyloid- $\beta$ plaques (Corsellis et al. 1973); and vascular amyloids (Tokuda et al. 1991). The severity of CTE can be related to the extent of NFTs and their distribution, as found post-mortem (McKee et al. 2013). At its early stages, CTE neurodegeneration is diagnosed through the perivascular accumulation of the NFTs below the sulci depth, which is usually observed in the frontal lobe (McKee et al. 2016). Greater severities are realized when NFTs are widespread and seen in high densities in cortical areas, thalamus, hypothalamus, and other brain regions (McKee et al. 2013; McKee et al. 2016). Considering the correlation of CTE localization with the negative curvature sulci during the early stages of neurodegeneration (McKee et al. 2016), the importance of understanding the effects of complex brain geometries and heterogeneities becomes apparent.

The human brain is both heterogeneous (white/gray matter, fractal vasculature) and anisotropic (e.g., radial cortical organization, oriented fiber tracts). Gray matter is located on the outer 
surface of the brain and contains numerous cell bodies and neuronal somas. The gray matter surrounds the white matter that mostly consists of myelinated axon tracts. In addition, to accommodate the large cortical sheet in a limited volume, the neocortical gray matter is more folded in large-brained animals (Allman). The gyri and sulci are the convex and concave folds of the cerebral cortex, respectively. The gyri often abut the inside surface of the cranium, except in major fissures or involutions such as the insula. The major cortical features (e.g., the Sylvian fissure and central sulcus) are readily identifiable with some detailed variation in the folding from person to person. The extent of brain convolutions also vary due to malformations, such as lissencephaly and polymicrogyria that enhance or reduce folding on the brain surface (Allman). Furthermore, the brain is encased in a multi-layered, fibrous structure that includes the pia, arachnoid, and dura mater, of which the pia mater is on the surface of the brain and follows its folds. An understanding of these features is then required to decide what features to include in a head model that can be achieved using computational approaches.

Computational head models (Horgan \& Gilchrist 2003; Takhounts et al. 2008; Ho et al. 2009; McAllister et al. 2012; Yang et al. 2014; Ghajari et al. 2017; Ganpule et al. 2017; Fernandes et al. 2018) informed from material constitutive models (Mendis et al. 1995; Donnelly et al. 1997; Arbogast \& Margulies 1999; el Sayed et al. 2008; Hosseini Farid et al. 2017; Hosseini-Farid et al. 2019) with various injury criteria (Newman 1986; Newman \& Shewchenko 2000; Kimpara \& Iwamoto 2012; Takhounts et al. 2013) are used to predict injury under various boundary conditions with some frameworks developed to specifically target injury (Horstemeyer et al. 2019). Some of these injury criteria implemented on macroscale head models included significant uncertainty when compared to neurological injury in real-world injury scenarios (Marjoux et al. 2008). Computational head models generally lack sulci in their brain geometries, which has been shown experimentally to produce heterogeneous von Mises strain fields with greater magnitudes close to sulci (Lauret et al. 2009). Macroscale head models that include sulci also have difficulty capturing the localization of such stress and strain concentrations (Ho \& Kleiven 2009; Song et al. 2015). More recently, researchers have used mesoscale brain tissue FE models with nonlocal mechanical damage to reproduce the localization of tau agglomarates under the sulcus base during shear shearing of the brain tissue (Noël \& Kuhl 2019). More detail on FE models looking at CTE and their comparison with the current work is presented in Appendix E. 
The contribution herein is a multiscale FE approach (motivated from a multiscale paradigm shown in Figure 1 (Murphy et al. 2016; A.H. Bakhtiarydavijani et al. 2019; Murphy et al. 2019; A. Bakhtiarydavijani et al. 2019). The multiscale paradigm depicted in Figure 1 tracks biomechancial features of brain injuries through different length scales that identify the most important variables at each length scale and bridges the information between scales. In the current work, the effects of local geometrical variations arising from sulci that are difficult to capture in macroscale FE head impact models are studied using mesoscale models considering the initial stress wave of impact. For this purpose, a set of mesoscale 2D brain FE simulations for which the boundary conditions were garnered from a previously validated macroscale FE whole head simulation, as shown in Figure 2, (Johnson et al. 2016) were used to evaluate the importance of the structural complexities at the mesoscale. The macroscale FE simulations represented the frontal head impact of an American football player wearing a helmet that was statistically the most significant head impact scenario in American football (Crisco et al. 2010). The mesoscale 2D FE simulations represent the frontal, occipital, temporal, and parietal lobes. These simulations consider structural and geometrical complexities, including gray matter, white matter, pia mater, and sulci, while also considering the brain-CerebroSpinal Fluid (CSF) interface properties. The boundary conditions of these mesoscale simulations are informed from the macroscale FE simulations. The resulting stress waves in the mesoscale 2D FE simulations are then discussed and compared to clinical studies of CTE, thus showing how this multiscale modelling approach can provide more accurate results without significantly increasing computational costs.

\section{Methods}

The macroscale whole head FE simulation included an American football player wearing a helmet. This simulation included the facemask, helmet shell, helmet liner, flesh, cortical and cancellous bone, cerebrospinal fluid (CSF), and the brain. The model was meshed with nearly 2.6 million elements (Johnson et al. 2016) and validated to Nahum et al. (Nahum et al. 1977). All simulations were performed in the explicit FE software Abaqus/Explicit ${ }^{\mathrm{TM}}$ (Dassault Systemes, Rhode Island, USA). The macroscale model with the Frankfort plane rotated forward, underwent a mid-sagittal head impact (Figure 2a) at $6 \mathrm{~m} / \mathrm{s}$. Average pressure-time histories, from four to five nodes that had insignificant $(<\% 5)$ variation for peak pressure, were extracted from the surface of the occipital lobe, parietal lobe, temporal lobe, and frontal lobe of the frontal head 
impact simulations as presented in Figure 2b. These pressure-time histories were then applied uniformly to their respective mesoscale 2D FE model described in the next section.

Two sets of mesoscale 2D FE simulations were used to evaluate (1) the effects of various material heterogeneities (Figure 3) and (2) the effects of sulci and gray matter in different brain lobes (Figure 4), when considering the pressures experienced during the frontal head impact. Table 1 presents a list of the FE simulations with the included anatomical features and brain lobes. The base simulation (Figure 3a) included two $25 \mathrm{~mm}$ deep, $1 \mathrm{~mm}$ wide sulci that were 16 $\mathrm{mm}$ apart. The brain tissue was differentiated into gray and white matter, where the gray matter had a $3 \mathrm{~mm}$ thickness. Figure $3 \mathrm{~b}$ shows the same sulci geometry but did not differentiate gray matter from white matter. Figure 3c shows differentiated gray-white matter but lacked sulci. Figure $3 \mathrm{~d}$ was made without sulci and did not differentiate between the gray and white matter. The effects of the brain-CSF interface were studied by varying the tangential friction coefficient as the following: 0 (frictionless), 0.075, 0.15, 0.30, and 1 (tied) in Figure 3a. A simulation with pia mater was also employed with a $0.1 \mathrm{~mm}$ one element thick viscoelastic membrane implemented, as shown in Figure 3 a between the CSF and the brain. Also, different lengths of a sulcus were analyzed as well. After identifying the most significant heterogeneities in the brain, the $2 \mathrm{D}$ geometry presented in Figure $3 \mathrm{a}$ was rotated to create geometries representing different brain lobes, as shown in Figure 4a. Here, the infinite boundary element was placed opposite to the incoming pressure wave (Figure $4 \mathrm{~b}$ through Figure 4e.). All simulations were performed in the explicit FE software Abaqus/Explicit ${ }^{\mathrm{TM}}$. These simulations modelled the first $4 \mathrm{~ms}$ of impact using a dynamic explicit step with no mass scaling. Forces were introduced as a uniform pressure on the loading surface.

\section{Material Properties}

The gray and white matter material properties were defined using the VUMAT MSU TP 1.1 material model that is an elasto-viscoplastic Internal State Variable (ISV) material model initially developed by (Francis et al. 2014) and used to model brain tissue (Prabhu et al. 2011; Johnson et al. 2016) (presented in Appendix A along with the calibrated constants from Johnson et al. (Johnson et al. 2016) presented in Table A.1). The CSF was treated as an incompressible elastic material and the pia mater as a viscoelastic material (Aimedieu \& Grebe 2004). The constants for these materials are presented in Table 2. 


\section{Boundary Conditions and Mesh}

All mesoscale 2D FE simulations used symmetric boundary conditions for boundaries adjacent to the loading surface, and an infinite boundary opposite of the loading surface that prevented pressure wave reflections at that surface. This boundary condition setup showed a good correlation with an extended geometry model that produced zero stress reflections. This was compared to simulations with three symmetric boundaries and three infinite boundary conditions, which gave unrealistic stresses and strains (Table 3). Hence, the single infinite boundary setup was used in all simulations. All simulations used reduced quadratic plane strain elements (Abaqus CPE4R) for the brain and infinite boundary elements (Abaqus CINPE4) for the infinite boundary. A mesh convergence study was performed (Figure 3a.) with 280,000; 30,000; and 9000 elements (or an element size of less than $0.5 \mathrm{~mm}$ for the latter mesh). The model with 9000 elements generated a result that was within 5\% standard error of the 280,000-element simulation when considering the average and peak pressure and, as such, was used for all simulations. To achieve more detailed field output gradients at the depth of the sulcus, the elements decreased to $0.1 \mathrm{~mm}$ below the sulcus.

\section{Results}

Figure 5 presents the von Mises stress and pressure in the frontal lobe during the frontal head impact of an American football player at the time of peak loading. The white arrows in Figure 5a show the direction of the pressure waves, while the gray double-headed arrows show the direction of the largest principal stress. Figures $5 \mathrm{~b}$ and $5 \mathrm{c}$ show Expanded views of the localization of pressure and von Mises stress around a sulcus, respectively.

Figures 6 and 7 present the von Mises stress and pressure evolution in the frontal lobe, respectively. Here, the four different structural heterogeneities shown in Figure 3 are considered. Figures 6a-c and 7a-c show these temporal evolutions for a simulation that includes sulci and graywhite matter differentiation with $\sigma_{v m}^{\max }$ and maximum pressure values of $18.0 \mathrm{kPa}$ and $131.0 \mathrm{kPa}$, respectively. Figures $6 \mathrm{~d}-\mathrm{f}$ and $7 \mathrm{~d}-\mathrm{f}$ show these values for a simulation that includes sulci and homogeneous brain material with $\sigma_{v m}^{\max }$ and maximum pressure values of $17.7 \mathrm{kPa}$ and $127.0 \mathrm{kPa}$, respectively. Figure $6 \mathrm{~g}-\mathrm{i}$ and Figure $7 \mathrm{~g}$-i only differentiate gray-white matter but do not include sulci and result in $\sigma_{v m}^{\max }$ and maximum pressure values of $0.6 \mathrm{kPa}$ and $122.7 \mathrm{kPa}$, respectively. 
Figure $6 \mathrm{j}-1$ and Figure $7 \mathrm{j}-1$ consider a homogenous brain material without sulci and result in $\sigma_{v m}^{\max }$ and maximum pressure values of $0.5 \mathrm{kPa}$ and $122.5 \mathrm{kPa}$, respectively.

Figure 8 shows the von Mises stress (Figure 8a-c) and pressure (Figure 8d-f) that developed under a $15 \mathrm{~mm}$ sulcus with the maximum values of $17.8 \mathrm{kPa}$ and $130.9 \mathrm{kPa}$, respectively. The effects of the sulcus length on the $\sigma_{v m}^{\max }$ during peak applied pressure are shown in Figure 8g-i, with the $\sigma_{v m}^{\max }$ increasing from $4.2 \mathrm{kPa}$ to $6.8 \mathrm{kPa}$ with increasing sulcus length.

Figures 9 and 10 show the von Mises stress and pressure histories in the four different brain lobes (Figure $4 b-e$ ). Figure $2 b$ shows the applied pressure boundary condition for each mesoscale simulation. The four rows in these figures are the evolution contours in the frontal, parietal, temporal, and occipital lobes, respectively. When sulci are parallel to the incoming pressure wave, both the von Mises stress and pressure initially localize below the sulci and move inward into the sulci depth as time progresses (Figures $9 \mathrm{c}$ and 91 ). When the sulci are perpendicular to the incoming pressure wave, stress concentrations localized below the sulci (Figures 9f and 9j). The pressure profiles also show peak stress concentrations below the sulci for all simulations. Table 4 summarizes the average and maximum von Mises stresses and pressures.

\section{Discussion}

The current work highlights the effectiveness of mesoscale FE simulations in capturing the relevant length scale geometrical complexities that are generally unattainable with macroscale FE simulations. The present 2D mesoscale FE simulations garner their boundary conditions from 3D macroscale FE simulations and are used to study the brain's geometric complexities and its correlation with CTE biomechanics in American football player head impact scenarios. Based on the aforementioned results, we observed that CTE initiation time and location are determined by two things: 1) structural heterogeneities, like sulci and gyri, that give rise to stress concentrators and gradients in the frontal, occipital, parietal, and temporal brain lobes and 2) the difference between the mechanical properties of the CSF and the brain. Thus, the brain's geometries and material heterogeneities were examined through mesoscale 2D FE simulations to determine their effects on the stress state and the limits of which can indicate injury (Chatelin et al. 2011). Specifically, the mesoscale 2D FE simulations accommodate the anatomical geometries of the brain's sulci and gyri, gray-white matter interface, and pia mater with a reasonable computational cost. This greater resolution provides a more detailed description of the stress 
wave propagation and the associated stress concentrations around the sulci. The locations of the stress concentrations correlated well with the sites of tau protein accumulation in Stage I CTE (McKee et al. 2016). Although the correlation between CTE and head impact has been clearly shown (Mez et al. 2017), the mechanism of CTE is still under study (Katsumoto et al. 2019). These stress concentrations were not captured in previous macroscale simulations (Ho \& Kleiven 2009; Song et al. 2015; Johnson et al. 2016). But, mesoscale brain models of brain tissue powered by elastic modulus softening, showed the strain energy localization under large shear strains perpendicular to the sulci (Noël \& Kuhl 2019).

When studying the von Mises stress $\left(\sigma_{v m}\right)$ evolution for a frontal head impact, the peak $\sigma_{v m}$ below the sulci for the frontal and occipital lobes were $18.0 \mathrm{kPa}$ and $19.1 \mathrm{kPa}$ (Table 4), respectively. In these brain lobes, $\sigma_{v M}$ initiated at the sulci end at the gray matter-CSF interface (Figures 9a, 9b, 9j, and 9k) and, with time, increased inward into the gray matter at the depth of the sulci forming a "cup shape" von Mises stress concentration region at the sulcus depth (Figures 9c and 91). At the same time, shear bands initiated from the sulci base that extended into the white matter, overlapping with those of other sulci to produce a secondary area of stress concentration when more than one sulcus was present.

Investigation of stress waves traversing in the vicinity of sulci showed that they affected the internal stresses in two different regimes, described here as near-field and far-field. In the nearfield, a sulcus produced local pressure and von Mises stress concentrations (white arrows in Figure $8 c$, Figures $6 \mathrm{c}$ and $6 \mathrm{f}$ compared to Figures $6 \mathrm{i}$ and 61$)$ at the sulci depth. This arose due to the impedance mismatch between the CSF and the brain tissue (Figure 5), causing the stress waves to travel slower in the CSF than in the brain tissue. As the faster pressure waves travelled in the brain matter adjacent to the sulcus and wrapped around the sulcus end (Figure 5b), they interacted with each other to form pressure and von Mises stress localizations (Figure 5c). This stress wave interaction was further complicated by the slower stress waves entering the gray matter through the CSF. The mismatch between the wave speeds in the brain and CSF further disrupted the pressure wavefront and intensified the maximum pressure localization near the sulci end (Figure 7c compared to Figure 71). When sulci were present the $\sigma_{v m}^{\max }$ increased by a little more than 39 times from $0.46 \mathrm{kPa}$ to $18.0 \mathrm{kPa}$ (Figure 61 compared to Figure $6 \mathrm{f}$ ). When comparing the FE simulation results with and without a sulcus, the increase in the maximum 
pressure was not as significant as that of the von Mises stress (maximum pressure increased by $7 \%$ from $122.5 \mathrm{kPa}$ to $131.0 \mathrm{kPa}$ (Figure $7 \mathrm{f}$ versus Figure 71 ) compared to 39 times). Thus, the simulations support the proposition that shear localization can be the proximal cause of neurodegeneration. Specifically, the near-field shear localization induced by the presence of sulci illustrates (Figure 6) the biomechanics of structural damage that lead to CTE (McKee et al. 2016).

The far-field effects of sulci arise from the inter-sulcus stress field interactions. When a single sulcus was present (Figure 8), shear bands that originated at the sulcus end extended into the brain tissue (Figure $8 \mathrm{c}$, circled white) resulting in $\sigma_{v M}^{\max }$ of $12 \mathrm{kPa}$. When another sulcus, of the same length, was introduced (Figure 6c and 6f, black arrows), the shear bands of the two sulci overlapped to produce a new area of stress localization with a $\sigma_{v M}^{\max }$ of $14.8 \mathrm{kPa}$ (Figure 9c) that was $23 \%$ greater than the $\sigma_{v M}^{\max }$ of measured in the one sulcus simulation (12 kPa, Figure $8 \mathrm{c}$, circled white). This far-field stress localization was not observed in scenarios where sulci were perpendicular to the incoming pressure wave (Figure 9h and 91). The location and existence of this far-field stress localization were found to be dependent on the sulcus length (Figure 8) and orientation (Figure 9) relative to the incoming pressure wave.

A previously published study has shown that large shear strains perpendicular to the sulci can localize the strain energy below the sulcus (Noël \& Kuhl 2019). This study had investigated one sulci orientation where the displacament boundary condition were applied perpendicular to the sulcus (Noël \& Kuhl 2019). Thus, in order to understand the influence of sulcus orientation to the impending pressure waves, we considered four sulci orientations with respect to the incoming pressure waves due to a frontal impact as observed in the frontal, pariental, temporal, and occipital lobes. This orientation aspect is important to consider, especially during a frontal head impact, which is statistically most significant head impact scenario in American football (Crisco et al. 2010). During a frontal head impact the pressure waves propagate parallel to the sulci in the frontal and occipital lobes, and perpendicular to the sulci in parietal and temporal lobes (McKee et al. 2016) (Figure 4). When studying the $\sigma_{v M}$ field in these mesoscale models, it was found that the $\sigma_{v M}^{\max }$ in the parallel configuration (frontal and occipital lobes) are significantly greater than that in the perpendicular orientation (temporal and parietal lobes), as presented in Table 4. Considering the locally applied pressures (Figure $2 \mathrm{~b}$ ) in conjunction with the $\sigma_{v M}^{\max }$ generated in 
Figure 9 leads to a better understanding of sulci effects on stress localization. During the head impact, sulci parallel to the pressure waves (frontal and occipital lobes) experienced peak pressures that were approximately an order of magnitude greater than the pressures in sulci perpendicular to the stress waves (parietal and temporal lobes). In contrast, the $\sigma_{v M}^{\max }$ in the perpendicular sulci was only two-thirds of those in the parallel sulci simulations (Table 4). Finally, although not reflected in this work, the frontal head impact may have a smaller effect in the occipital lobe due to wave dispersion or defocusing as it traverses through the brain.

The sulcus length was found to affect the near-field stress concentrations when the impending pressure waves traversed through the CSF and flanked the gray matter of the sulcus. By increasing the sulcus length from $7.5 \mathrm{~mm}$ to $24.5 \mathrm{~mm}$, the $\sigma_{v M}^{\max }$ increased below the sulcus end by approximately $9 \%$, from $16.6 \mathrm{kPa}$ to $18.1 \mathrm{kPa}$ (Table 4 and Figure $8 \mathrm{~g}-\mathrm{i}$ ). This increase could be related to the increased mismatch between the stress wavefronts traveling in the CSF and gray matter (Figure C1 in Appendix C). In the far-field, the length of the shear bands was proportional to the sulcus length but had only minor effects on the magnitude of the von Mises stress in those bands (Figure 8g-i). The larger area covered by these stress bands means that more brain tissue may be susceptible to injury with longer sulci. These effects may be compounded by brain malformations, such as lissencephaly and polymicrogyria (Budday et al. 2015). Accordingly, the susceptibility of individuals with such conditions to blunt impact head trauma should differ from those without the susceptibility.

\section{Conclusions}

In this work, pressure-time boundary conditions extracted from macroscale human head Finite Element (FE) simulations were used to study stress wave propagations in mesoscale 2D FE simulations of the brain sulcus-gyrus geometries and material heterogeneities in four different brain lobes (frontal, parietal, temporal, and occipital). The following were the salient observations:

- The impedance mismatch of the CSF and the gray matter (Figure 5) produced a variation in the wave propagation speeds in CSF and gray matter that resulted in the complex local interaction of the two stress waves (on both sides of a sulcus) and a 
wavefront in the CSF at the sulcus end. These stress wave interactions synergistically increased the von Mises (shearing) stress in the near- and far-field of the sulci.

- In the near-field, a sulcus introduces a von Mises stress localization just below the sulcus end (Figure 5.c) that was 39 times greater than those experienced in simulations without sulci (Figure 6.f and 6.i and Table 4). These stress concentrations below the sulci provide a mechanism for the corresponding localized damage (tau protein accumulation) observed during the early stages of CTE in the literature.

- In the far-field, shear stress bands emanate from the sulcal ends (Figure 8.c-white circle) and interact with one another to produce von Mises stress concentrations in the brain tissue (Figure 6.c and f-black arrow) that are $23 \%$ greater in magnitude compared to single sulcus simulations. The magnitude and extent of this stress concentration are dependent on the sulci lengths, orientations, and nearest neighbour distances from each other.

- Increasing the sulcus length from $7.5 \mathrm{~mm}$ to $24.5 \mathrm{~mm}$ increased the resulting von Mises stress concentration by $9 \%$ (Figure 8.g-i and Table 4) and produced large von Mises stresses that extended further into the white matter.

- Differentiating between gray and white matter, even with different elasto-viscoplastic constitutive properties, produced small von Mises stress concentrations at the graywhite matter interface when compared to stresses of sulci (Figure 6.c and Table 4). Accounting for sulci presence is essential to modelling the biomechanical causes of CTE.

- Varying the brain-CSF numerical interaction (frictionless, tied, and varying the tangential friction coefficients from $7.5 \%$ to $30 \%$ ) and introducing pia matter into the 
simulation did not significantly affect the stress wave propagation nor the localization of von Mises stress (Appendix D).

Finally, the current study shows how multiscale FE simulations with whole head FE simulations providing the boundary conditions for lower length scale mesoscale FE simulations can provide a more detailed understanding of regions prone to injury without significant increases in computational costs.

\section{Acknowledgments}

The authors would like acknowledge the Center for Advanced Vehicular Systems (CAVS) at Mississippi State University for supporting this work.

Competing interests: None declared

Funding: None

Ethical approval: Not required 


\section{References}

Aimedieu P, Grebe R. 2004. Tensile strength of cranial pia mater: preliminary results. Journal of Neurosurgery [Internet]. 100(1):111-114. http://thejns.org/doi/abs/10.3171/jns.2004.100.1.0111

Allman JM. Evolving Brains 2000 [Internet]. [place unknown]; [accessed 2019 Dec 29]. www.nhoj.info

Arbogast KB, Margulies SS. 1999. A fiber-reinforced composite model of the viscoelastic behavior of the brainstem in shear. Journal of Biomechanics [Internet]. [accessed 2017 Aug 12] 32(8):865-870. https://www.sciencedirect.com/science/article/pii/S0021929099000421

Bailes JE, Petraglia AL, Omalu BI, Nauman E, Talavage T. 2013. Role of subconcussion in repetitive mild traumatic brain injury. Journal of Neurosurgery [Internet]. [accessed 2017 Aug 9] 119(5):1235-1245. http://thejns.org/doi/10.3171/2013.7.JNS121822

Bakhtiarydavijani A, Murphy MA, Mun S, Jones MD, Bammann DJ, Laplaca MC, Horstemeyer MF, Prabhu RK. 2019. Damage biomechanics for neuronal membrane mechanoporation. Modelling and Simulation in Materials Science and Engineering. 27(6).

Bakhtiarydavijani AH, Murphy MA, Mun S, Jones MD, Horstemeyer MF, Prabhu RK. 2019. Multiscale Modeling of the Damage Biomechanics of Traumatic Brain Injury. Biophysical Journal. 116(3):322a.

Budday S, Raybaud C, Kuhl E. 2015. A mechanical model predicts morphological abnormalities in the developing human brain. Scientific Reports [Internet]. [accessed 2018 Mar 5] 4(1):5644. http://www.nature.com/articles/srep05644

Cajigal S. 2007. Brain Damage May Have Contributed to Former Wrestler's Violent Demise. Neurology Today [Internet]. [accessed 2018 Apr 15] 7(18):1.

https://insights.ovid.com/crossref?an=00132985-200709180-00001

Chatelin S, Deck C, Renard F, Kremer S, Heinrich C, Armspach J-P, Willinger R. 2011. Computation of axonal elongation in head trauma finite element simulation. Journal of the Mechanical Behavior of Biomedical Materials [Internet]. [accessed 2017 Aug 12] 4(8):19051919. https://www.sciencedirect.com/science/article/pii/S175161611100155X 
Corsellis JA, Bruton CJ, Freeman-Browne D. 1973. The aftermath of boxing. Psychological medicine [Internet]. [accessed 2018 May 15] 3(3):270-303.

http://www.ncbi.nlm.nih.gov/pubmed/4729191

Crisco JJ, Fiore R, Beckwith JG, Chu JJ, Brolinson PG, Duma S, McAllister TW, Duhaime A-C, Greenwald RM. 2010. Frequency and location of head impact exposures in individual collegiate football players. Journal of athletic training [Internet]. [accessed 2018 Apr 10] 45(6):549-59. http://www.ncbi.nlm.nih.gov/pubmed/21062178

Donnelly BR, Medige J, Medige J, Donnelly BR, Medige J. 1997. Shear properties of human brain tissue. Journal of Biomechanical Engineering [Internet]. [accessed 2018 Jul 12] 119(4):423-432. http://files/476/579867.pdf

Fernandes FAO, Tchepel D, Alves De Sousa RJ, Ptak M. 2018. Development and validation of a new finite element human head model Yet another head model (YEAHM). Engineering Computations [Internet]. [accessed 2020 Jan 30] 35:477-496. www.emeraldinsight.com/02644401.htm

Francis DK, Bouvard JL, Hammi Y, Horstemeyer MF. 2014. Formulation of a damage internal state variable model for amorphous glassy polymers. International Journal of Solids and Structures.

Ganpule S, Daphalapurkar NP, Ramesh KT, Knutsen AK, Pham DL, Bayly P v., Prince JL. 2017. A Three-Dimensional Computational Human Head Model That Captures Live Human Brain Dynamics. Journal of Neurotrauma [Internet]. [accessed 2020 Jan 30] 34(13):2154-2166. http://www.liebertpub.com/doi/10.1089/neu.2016.4744

Geddes JF, Vowles GH, Nicoll JAR, Révész T. 1999. Neuronal cytoskeletal changes are an early consequence of repetitive head injury. Acta Neuropathologica [Internet]. [accessed 2018 Apr 4] 98(2):171-178. http://link.springer.com/10.1007/s004010051066

Ghajari M, Hellyer PJ, Sharp DJ. 2017. Computational modelling of traumatic brain injury predicts the location of chronic traumatic encephalopathy pathology. Brain [Internet]. [accessed 2017 Sep 12] 140(2):333-343. https://academic.oup.com/brain/articlelookup/doi/10.1093/brain/aww317 
Guskiewicz KM, Marshall SW, Bailes, Julian McCrea M, Harding HP, Matthews A, Mihalik JR, Cantu RC. 2007. Recurrent Concussion and Risk of Depression in Retired Professional Football Players. Medicine \& Science in Sports \& Exercise [Internet]. [accessed 2018 Apr 15] 39(6):903909. http://www.ncbi.nlm.nih.gov/pubmed/17545878

Ho J, von Holst H, Kleiven S. 2009. Automatic generation and validation of patient-specific finite element head models suitable for crashworthiness analysis. International Journal of Crashworthiness. 14(6):555-563.

Ho J, Kleiven S. 2009. Can sulci protect the brain from traumatic injury? Journal of Biomechanics [Internet]. [accessed 2018 Apr 19] 42(13):2074-2080. http://www.sciencedirect.com/science/article/pii/S0021929009003364

Hof PR, Knabe R, Bovier P, Bouras C. 1991. Neuropathological observations in a case of autism presenting with self-injury behavior. Acta Neuropathologica [Internet]. [accessed 2018 Apr 4] 82(4):321-326. http://link.springer.com/10.1007/BF00308819

Horgan TJ, Gilchrist MD. 2003. The creation of three-dimensional finite element models for simulating head impact biomechanics. International Journal of Crashworthiness [Internet]. 8(4):353-366. http://link.springer.com/article/10.1533/ijcr.2003.0243

Horstemeyer MF, Berthelson PR, Moore J, Persons AK, Dobbins A, Prabhu RK. 2019. A Mechanical Brain Damage Framework Used to Model Abnormal Brain Tau Protein Accumulations of National Football League Players. Annals of Biomedical Engineering. 47(9):1873-1888.

Hosseini Farid M, Eslaminejad A, Ziejewski M, Karami G. 2017. A Study on the Effects of Strain Rates on Characteristics of Brain Tissue. In: Volume 3: Biomedical and Biotechnology Engineering [Internet]. [place unknown]: ASME; [accessed 2018 Jul 13]; p. V003T04A003. http://proceedings.asmedigitalcollection.asme.org/proceeding.aspx?doi=10.1115/IMECE201770356

Hosseini-Farid M, Ramzanpour M, Ziejewski M, Karami G. 2019. A compressible hyperviscoelastic material constitutive model for human brain tissue and the identification of its parameters. International Journal of Non-Linear Mechanics. 116:147-154. 
Johnson KLL, Chowdhury S, Lawrimore WBB, Mao Y, Mehmani A, Prabhu R, Rush GAA, Horstemeyer MFF. 2016. Constrained topological optimization of a football helmet facemask based on brain response. Materials \& Design [Internet]. [accessed 2018 May 16] 111:108-118. https://www.sciencedirect.com/science/article/pii/S0264127516311273

Katsumoto A, Takeuchi H, Tanaka F. 2019. Tau Pathology in Chronic Traumatic Encephalopathy and Alzheimer's Disease: Similarities and Differences. Frontiers in Neurology | Www.frontiersin.org [Internet]. [accessed 2019 Nov 19] 10:980. www.frontiersin.org

Kimpara H, Iwamoto M. 2012. Mild traumatic brain injury predictors based on angular accelerations during impacts. Annals of Biomedical Engineering. 40(1):114-126.

Lauret C, Hrapko M, van Dommelen JAWAW, Peters GWMWM, Wismans JSHMSHM. 2009. Optical characterization of acceleration-induced strain fields in inhomogeneous brain slices. Medical Engineering \& Physics [Internet]. [accessed 2018 Apr 19] 31(3):392-399. http://www.sciencedirect.com/science/article/pii/S1350453308000842

Marjoux D, Baumgartner D, Deck C, Willinger R. 2008. Head injury prediction capability of the HIC, HIP, SIMon and ULP criteria. Accident Analysis \& Prevention [Internet]. [accessed 2018 Jul 15] 40(3):1135-1148.

https://www.sciencedirect.com/science/article/pii/S0001457507002175?via\%3Dihub

McAllister TW, Ford JC, Ji S, Beckwith JG, Flashman LA, Paulsen K, Greenwald RM. 2012. Maximum principal strain and strain rate associated with concussion diagnosis correlates with changes in corpus callosum white matter indices. Annals of Biomedical Engineering. 40(1):127140.

McCrea M, Guskiewicz KM, Marshall SW, Barr W, Randolph C, Cantu RC, Onate JA, Yang J, Kelly JP. 2003. Acute Effects and Recovery Time Following Concussion in Collegiate Football Players. JAMA [Internet]. [accessed 2018 Apr 15] 290(19):2556.

http://jama.jamanetwork.com/article.aspx?doi=10.1001/jama.290.19.2556

McKee AC, Cairns NJ, Dickson DW, Folkerth RD, Keene CD, Litvan I, Perl DP, Stein TD, Vonsattel J-P, Stewart W, et al. 2016. The first NINDS/NIBIB consensus meeting to define neuropathological criteria for the diagnosis of chronic traumatic encephalopathy. Acta 
neuropathologica [Internet]. [accessed 2017 Aug 9] 131(1):75-86.

http://www.ncbi.nlm.nih.gov/pubmed/26667418

McKee AC, Stern RA, Nowinski CJ, Stein TD, Alvarez VE, Daneshvar DH, Lee H-S, Wojtowicz SM, Hall G, Baugh CM, et al. 2013. The spectrum of disease in chronic traumatic encephalopathy. Brain : a journal of neurology [Internet]. [accessed 2018 Apr 4] 136(Pt 1):4364. http://www.ncbi.nlm.nih.gov/pubmed/23208308

Mendis KK, Stalnaker RL, Advani SH. 1995. A Constitutive Relationship for Large Deformation Finite Element Modeling of Brain Tissue. Journal of Biomechanical Engineering [Internet]. 117(3):279-285. http://dx.doi.org/10.1115/1.2794182

Mez J, Daneshvar DH, Kiernan PT, Abdolmohammadi B, Alvarez VE, Huber BR, Alosco ML, Solomon TM, Nowinski CJ, McHale L, et al. 2017. Clinicopathological Evaluation of Chronic Traumatic Encephalopathy in Players of American Football. JAMA [Internet]. [accessed 2017 Aug 23] 318(4):360-370. http://jamanetwork.com/journals/jama/fullarticle/2645104

Murphy MA, Horstemeyer MFF, Gwaltney SR, Stone T, LaPlaca MC, Liao J, Williams LN, Prabhu R, Stone T, LaPlaca MC, et al. 2016. Nanomechanics of phospholipid bilayer failure under strip biaxial stretching using molecular dynamics. Modelling and Simulation in Materials Science and Engineering [Internet]. 24(5):55008. http://stacks.iop.org/0965$0393 / 24 / \mathrm{i}=5 / \mathrm{a}=055008$

Murphy MA, Mun S, Horstemeyer MF, Baskes MI, Bakhtiary A, LaPlaca MC, Gwaltney SR, Williams LN, Prabhu RK. 2019. Molecular dynamics simulations showing 1-palmitoyl-2-oleoylphosphatidylcholine (POPC) membrane mechanoporation damage under different strain paths. Journal of Biomolecular Structure and Dynamics [Internet]. [accessed 2019 May 24] 37(5):1346-1359. https://www.tandfonline.com/doi/full/10.1080/07391102.2018.1453376

Nahum AM, Smith R, Ward CC. 1977. Intracranial Pressure Dynamics During Head Impact. Proceedings of the 21st Stapp Car Crash Conference [Internet]. [accessed 2018 Jan 20]:339-366. http://papers.sae.org/770922/

Newman JA. 1986. A generalized acceleration model for brain injury threshold (GAMBIT). 
Newman JA, Shewchenko N. 2000. A Proposed New Biomechanical Head Injury Assessment Function - The Maximum Power Index. In: SAE Technical Papers. Vol. 2000-Novem. [place unknown]: SAE International.

Noël L, Kuhl E. 2019. Modeling neurodegeneration in chronic traumatic encephalopathy using gradient damage models. Computational Mechanics. 64(5):1375-1387.

Omalu BI, DeKosky ST, Minster RL, Kamboh MI, Hamilton RL, Wecht CH. 2005. Chronic Traumatic Encephalopathy in a National Football League Player. Neurosurgery [Internet]. [accessed 2017 Aug 27] 57(1):128-134. https://academic.oup.com/neurosurgery/articlelookup/doi/10.1227/01.NEU.0000163407.92769.ED

Parker HL. 1934. Traumatic Encephalopathy ('Punch Drunk') of Professional Pugilists. The Journal of neurology and psychopathology [Internet]. [accessed 2017 Aug 22] 15(57):20-8. http://www.ncbi.nlm.nih.gov/pubmed/21610785

Prabhu R, Horstemeyer MFF, Tucker MTT, Marin EBB, Bouvard JLL, Sherburn JAA, Liao J, Williams LN. 2011. Coupled experiment/finite element analysis on the mechanical response of porcine brain under high strain rates. Journal of the Mechanical Behavior of Biomedical Materials [Internet]. [accessed 2018 Jul 13] 4(7):1067-1080.

https://www.sciencedirect.com/science/article/pii/S1751616111000609

Saing T, Dick M, Nelson PT, Kim RC, Cribbs DH, Head E. 2012. Frontal Cortex

Neuropathology in Dementia Pugilistica. Journal of Neurotrauma [Internet]. [accessed 2018 Apr 4] 29(6):1054-1070. http://www.ncbi.nlm.nih.gov/pubmed/22017610

el Sayed T, Mota A, Fraternali F, Ortiz M. 2008. A variational constitutive model for soft biological tissues. Journal of Biomechanics [Internet]. 41(7):1458-1466. http://www.sciencedirect.com/science/article/pii/S0021929008000778

Song X, Wang C, Hu H, Huang T, Jin J. 2015. A Finite Element Study of the Dynamic Response of Brain Based on Two Parasagittal Slice Models. Computational and Mathematical Methods in Medicine [Internet]. [accessed 2018 Apr 4] 2015:1-14.

http://www.hindawi.com/journals/cmmm/2015/816405/ 
Takhounts EG, Craig MJ, Moorhouse K, McFadden J, Hasija V. 2013. Development of brain injury criteria (BrIC). Stapp car crash journal. 57:243-266.

Takhounts EG, Ridella SA, Hasija V, Tannous RE, Campbell JQ, Malone D, Danelson K, Stitzel J, Rowson S, Duma S. 2008. Investigation of traumatic brain injuries using the next generation of simulated injury monitor (SIMon) finite element head model. Stapp car crash journal. 52:131.

Tokuda T, Ikeda S, Yanagisawa N, Ihara Y, Glenner GG. 1991. Re-examination of ex-boxers' brains using immunohistochemistry with antibodies to amyloid ?-protein and tau protein. Acta Neuropathologica [Internet]. [accessed 2018 May 15] 82(4):280-285.

http://link.springer.com/10.1007/BF00308813

Yang B, Tse KM, Chen N, Tan L bin, Zheng QQ, Yang HM, Hu M, Pan G, Lee HP. 2014.

Development of a finite element head model for the study of impact head injury. BioMed Research International. 2014. 


\section{Figures and tables}

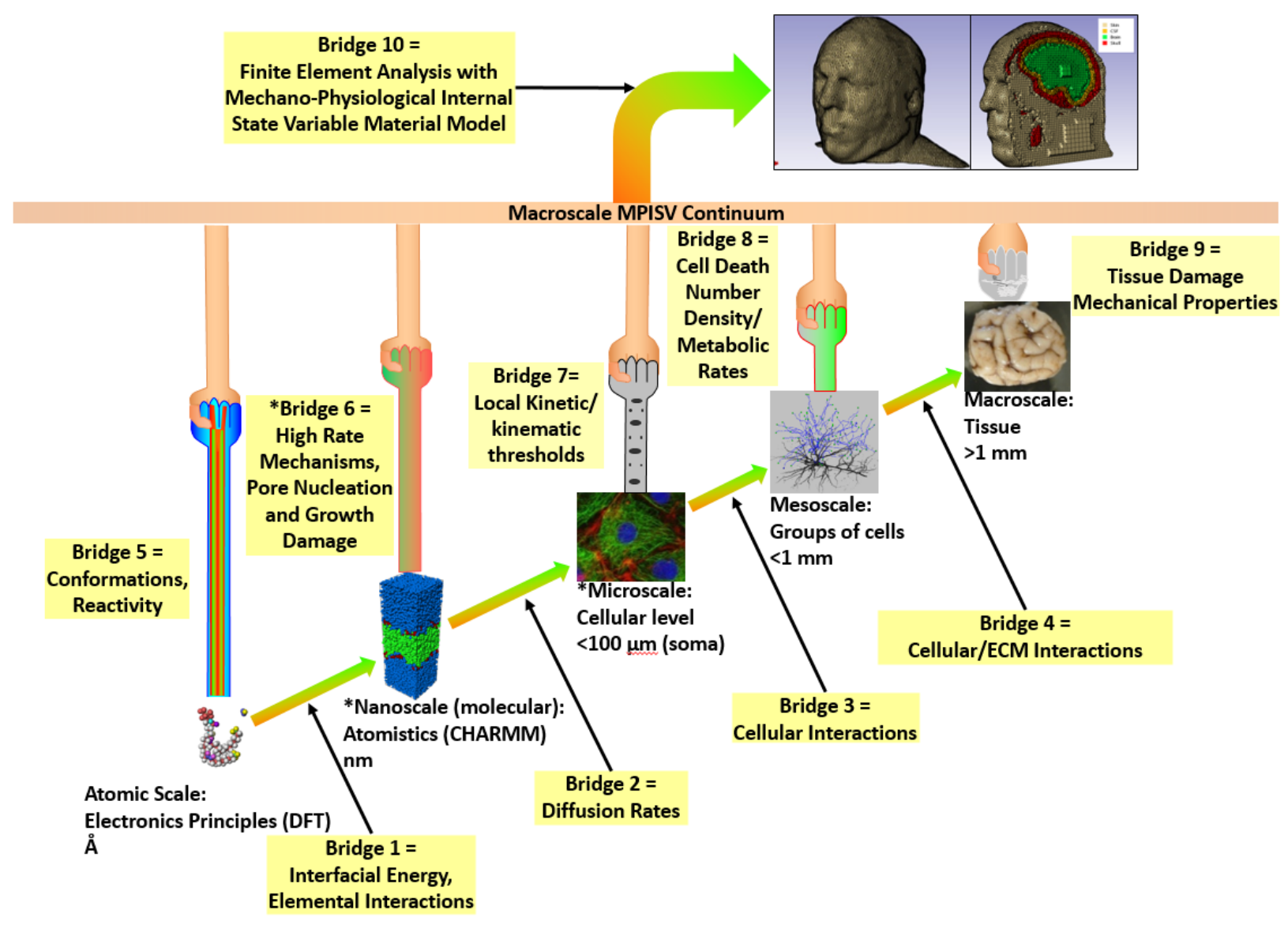

Figure 1. Multiscale approach to modeling neuronal mechanical behavior as it relates to the mechano-physiological internal state variables (MPISV). Modified from Murphy et al. (2016). 

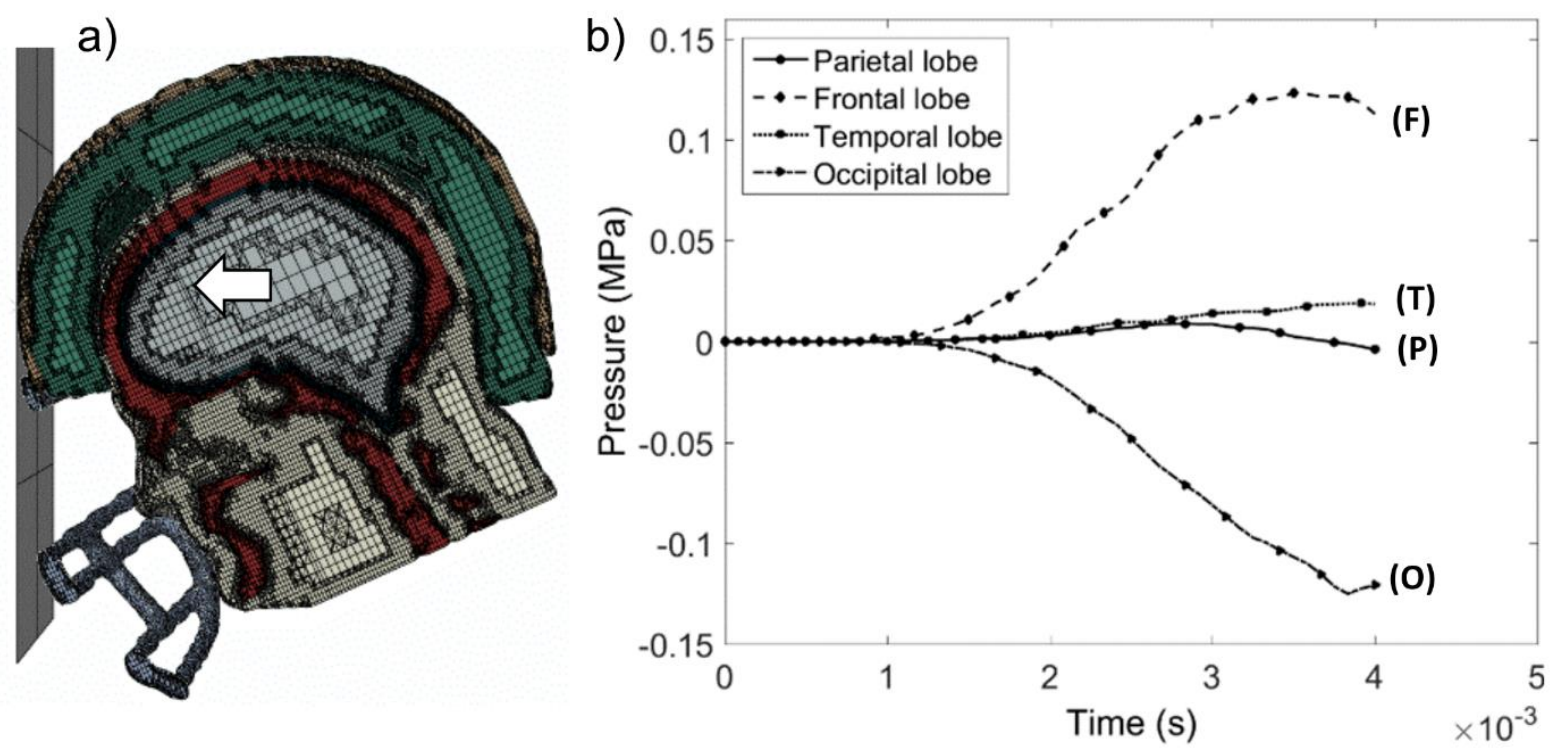

Figure 2. a) Sagittal-cut plane view of the macroscale human head blunt impact finite element model showing the frontal head impact of a helmeted American football player with the white arrow showing the head movement direction and $b$ ) the resulting pressure-time histories extracted from the surface of the brain lobes. 
Table 1. List of the two-dimensional (2D) finite element (FE) models considering the anatomical features, locations, and impact scenario.

\begin{tabular}{|c|c|c|c|c|c|}
\hline Input Load & $\begin{array}{c}\text { Gray-White } \\
\text { Matter } \\
\text { Differentiation }\end{array}$ & $\begin{array}{l}\text { Sulcus Length } \\
\text { (mm) }\end{array}$ & $\begin{array}{c}\text { Pia } \\
\text { Mater }\end{array}$ & $\begin{array}{l}\text { Brain-CSF } \\
\text { Interface }\end{array}$ & Lobe \\
\hline \multirow{12}{*}{$\begin{array}{l}\text { Football } \\
\text { blunt } \\
\text { impact-two } \\
\text { sulci }\end{array}$} & \multirow{2}{*}{ No } & n\a & n\a & Tied & Frontal \\
\hline & & 15 & n\a & Tied & Frontal \\
\hline & \multirow{10}{*}{ Yes } & nla & n\a & Tied & Frontal \\
\hline & & 15 & $\mathrm{n} \backslash \mathrm{a}$ & Tied & Frontal \\
\hline & & 15 & $0.2 \mathrm{~mm}$ & Tied & Frontal \\
\hline & & 15 & $\mathrm{n} \backslash \mathrm{a}$ & Frictionless & Frontal \\
\hline & & 15 & n\a & $7.5 \%$ & Frontal \\
\hline & & 15 & nla & $15 \%$ & Frontal \\
\hline & & 15 & n\a & $30 \%$ & Frontal \\
\hline & & 15 & n\a & Tied & Tempora \\
\hline & & 15 & n\a & Tied & Occipital \\
\hline & & 15 & $\mathrm{n} \backslash \mathrm{a}$ & Tied & Parietal \\
\hline \multirow{3}{*}{$\begin{array}{l}\text { Football } \\
\text { blunt } \\
\text { impact-one } \\
\text { sulcus }\end{array}$} & \multirow{3}{*}{ Yes } & 7.5 & nla & Tied & Frontal \\
\hline & & 15 & $\mathrm{n} \backslash \mathrm{a}$ & Tied & Frontal \\
\hline & & 24.5 & nla & Tied & Frontal \\
\hline
\end{tabular}



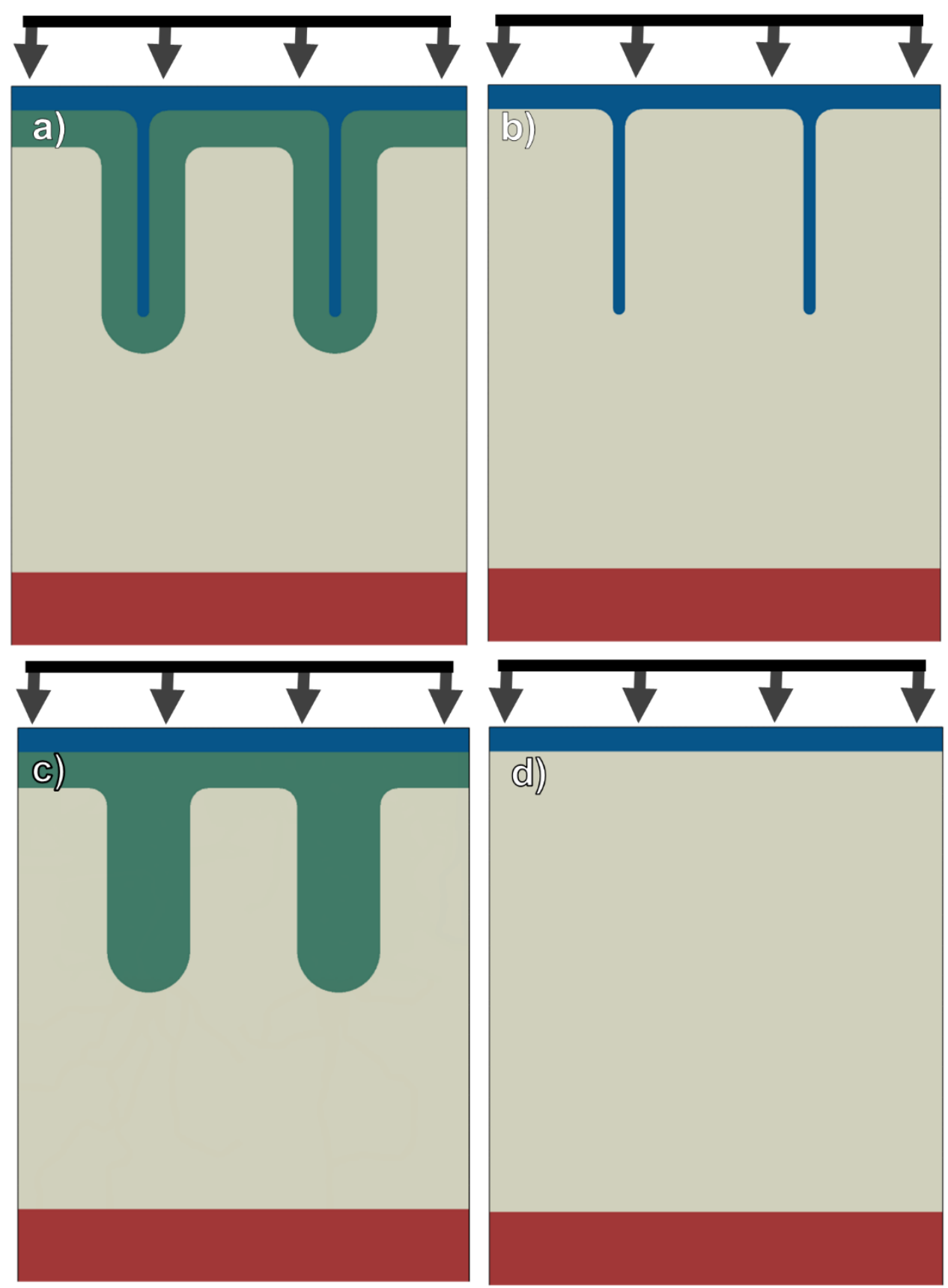

Figure 3. Mesoscale 2D Finite Element (FE) Geometries used to study the effects of structural complexities under the frontal American football player blunt head impact where blue, green, gray, and maroon represent the CSF, gray matter, white matter, and infinite boundary element, respectively. These FE geometries include: a) gray matter, white matter and sulci, b) sulci and homogeneous brain, c) gray matter and white matter, and d) homogeneous brain. 


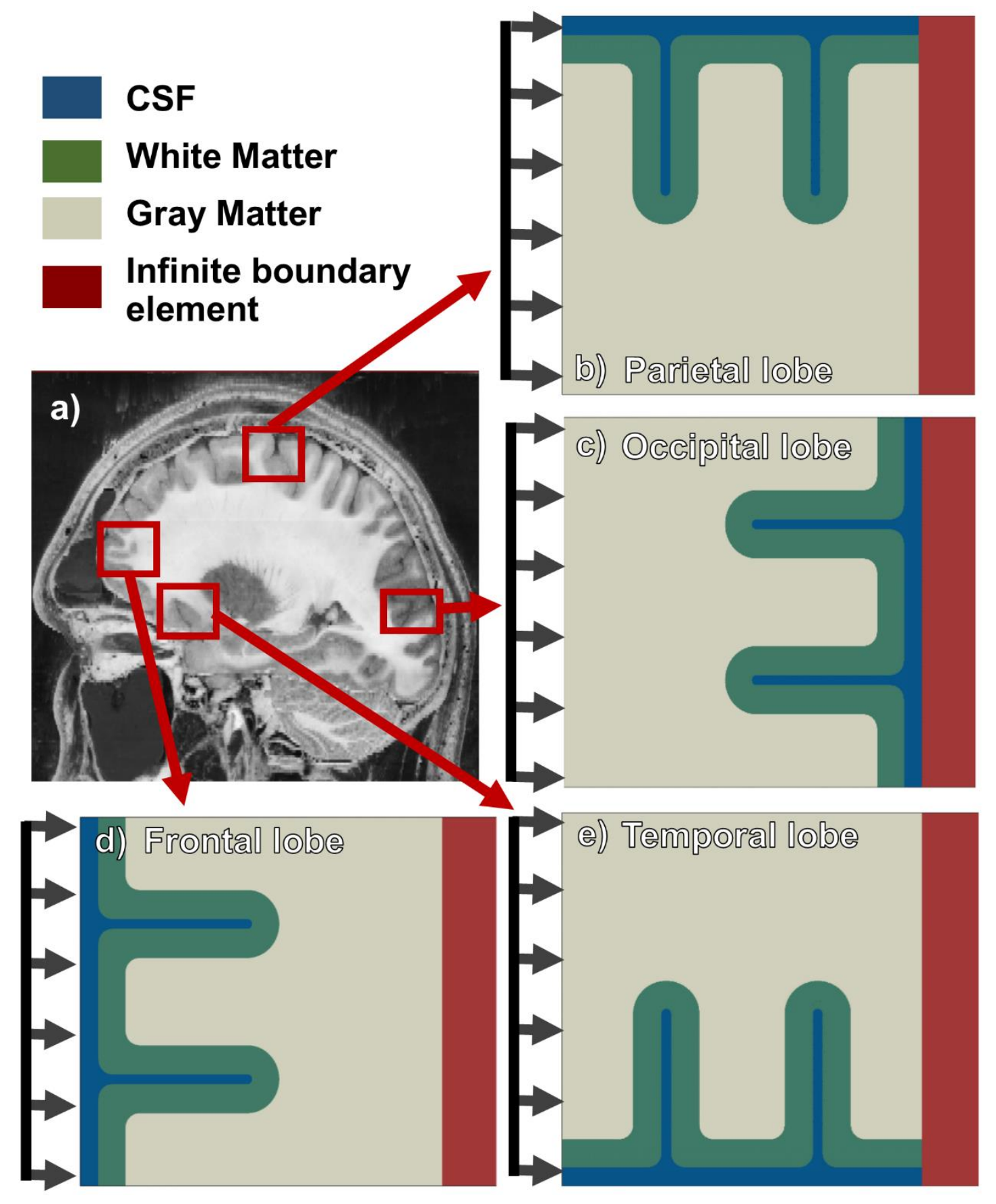

Figure 4. a) Magnetic Resonance Image (MRI) shown as a representative for the parasagittal plane of the human brain with locations highlighted correlating to two-dimensional finite element models of b) the Parietal lobe, c) Occipital lobe, d) the frontal lobe, and e) the temporal lobe with uniform loading direction for the frontal head impact scenario. 
Table 2. Material properties of the head for the mesoscale finite element simulations.

\begin{tabular}{|c|c|c|c|c|c|}
\hline & Density $\boldsymbol{\rho}\left(\mathbf{g} / \mathbf{c m}^{\mathbf{3}}\right)$ & Poisson's Ratio & $\begin{array}{c}\text { Elastic } \\
\text { Modulus } \\
(\mathbf{M P a})\end{array}$ & $\begin{array}{c}\text { Relaxation } \\
(\mathbf{s})\end{array}$ & Decay \\
\hline Pia Mater & 1.040 & 0.450 & 20.00 & 0.919 & 2 \\
\hline CSF & 1.004 & 0.495 & 0.15 & & \\
\hline Gray Matter & See Appendix I & & \\
\hline White Matter & See Appendix I & & \\
\hline
\end{tabular}


Table 3. Validating boundary condition elements in mesoscale 2D Finite Element (FE) simulations of the frontal lobe during the frontal head impact of a football player. The table presents the localized stresses and strains below the sulcus and the average pressure of the whole model.

\begin{tabular}{|c|c|c|c|c|c|}
\hline Model & $\begin{array}{c}\text { Average } \\
\text { element } \\
\text { length (mm) }\end{array}$ & $\begin{array}{c}\boldsymbol{\sigma}_{\boldsymbol{v m}} \\
\mathbf{( k P a )}\end{array}$ & $\begin{array}{c}\text { Peak } \\
\text { Pressure } \\
\mathbf{( k P a )}\end{array}$ & $\boldsymbol{\varepsilon}_{\mathbf{1}}$ & $\begin{array}{c}\text { Average } \\
\text { pressure } \\
(\mathbf{k P a})\end{array}$ \\
\hline $\begin{array}{c}\text { Periodic/ infinite } \\
\text { boundary element } \\
\text { model }\end{array}$ & 0.5 & 17.93 & 130.0 & 0.02355 & 115.25 \\
\hline $\begin{array}{c}\text { Extended } \\
\text { geometry model }\end{array}$ & 0.5 & 16.70 & 136.5 & 0.02556 & 119.74 \\
\hline $\begin{array}{c}\text { All periodic } \\
\text { boundary model }\end{array}$ & 0.5 & 285 & 106.8 & 0.1802 & 76.25 \\
\hline
\end{tabular}



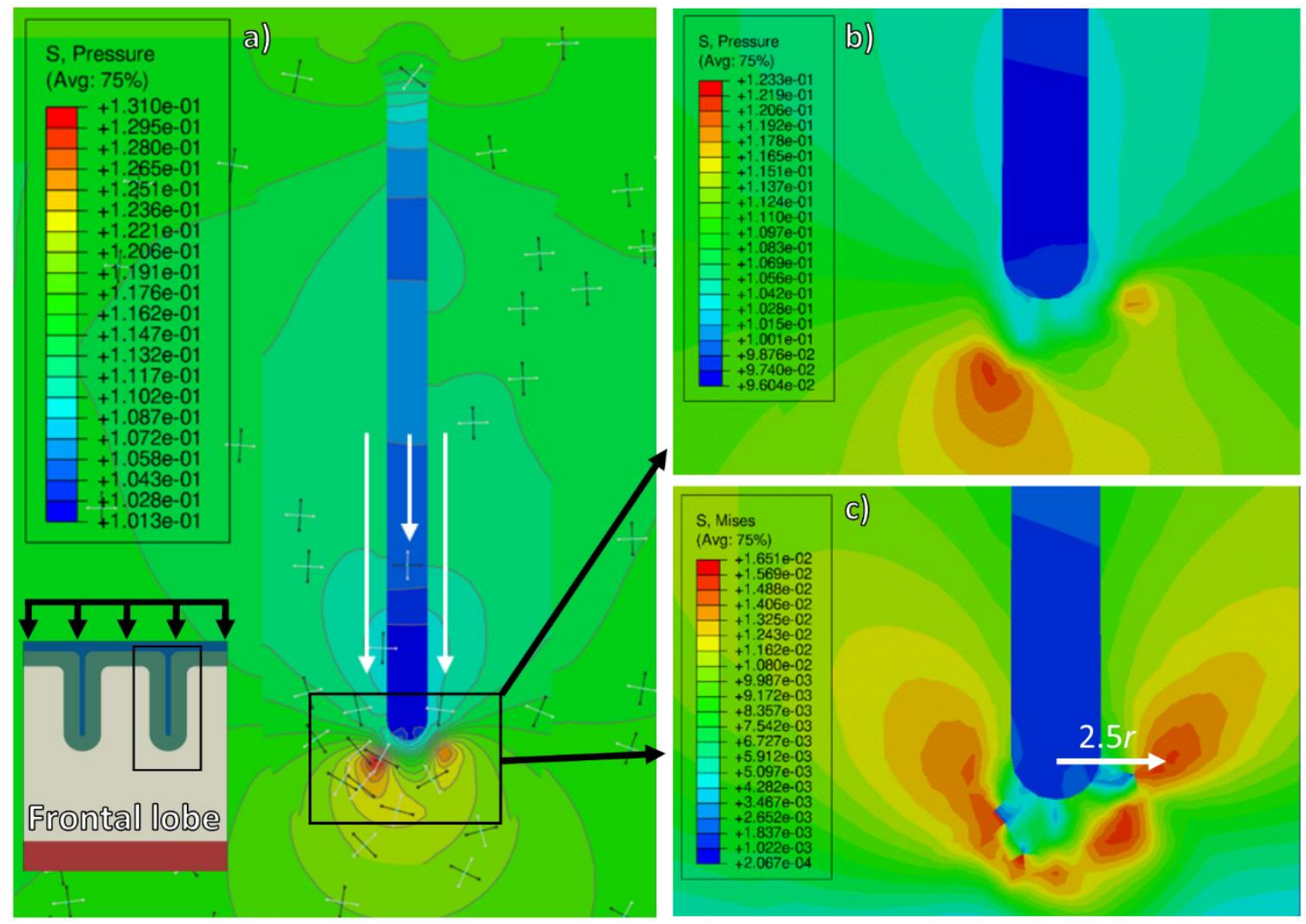

Figure 5. Mesoscale 2D Finite Element (FE) simulations of the Pressure and von Mises stress (MPa) localization below the sulcus in the frontal lobe of a football player experiencing a frontal head impact at $3.85 \mathrm{~ms}$. a) Pressure wave propagation during peak pressures, showing slower wave speeds in the CSF compared to brain. The small gray double headed arrows show the direction of the maximum peak principal stress, and the white arrows show the direction of the stress wave propagation. b) The localization of pressure below the sulcus arises from the geometrical complexity (sulcus), and the interaction of the two pressure waves on either side of the sulcus. c) The von Mises stress localization arising from the pressure field below the sulcus. 


\section{S, Mises}

(Avg: $75 \%$ )

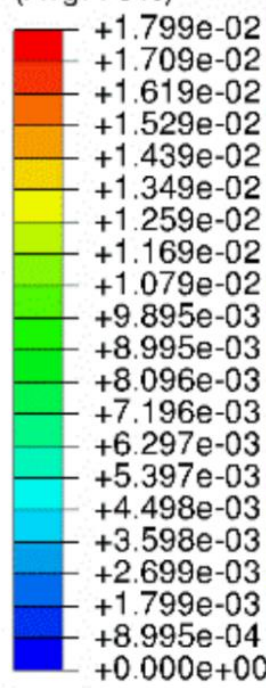

S, Mises

(Avg: $75 \%$ )

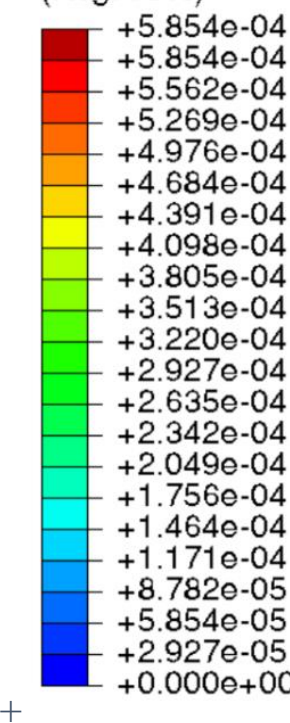

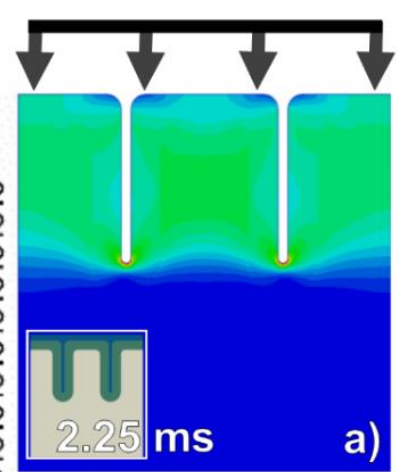
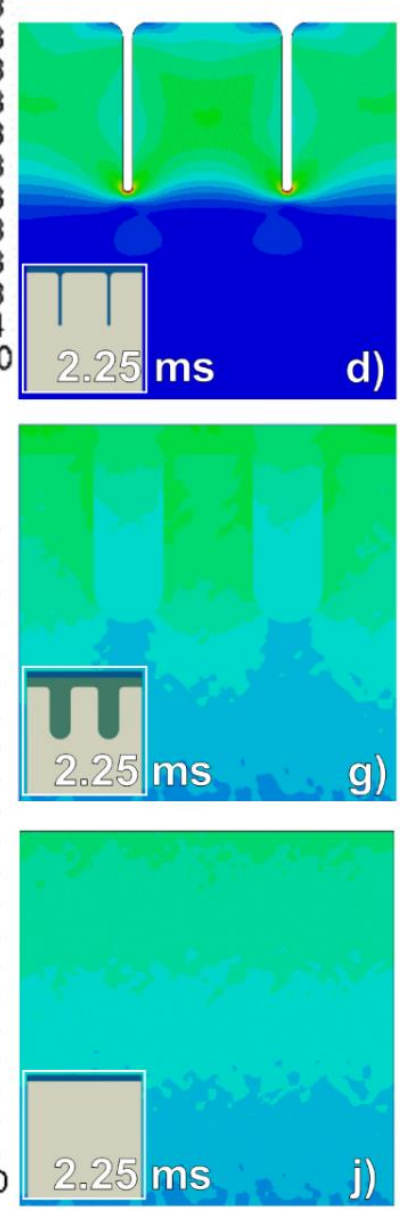
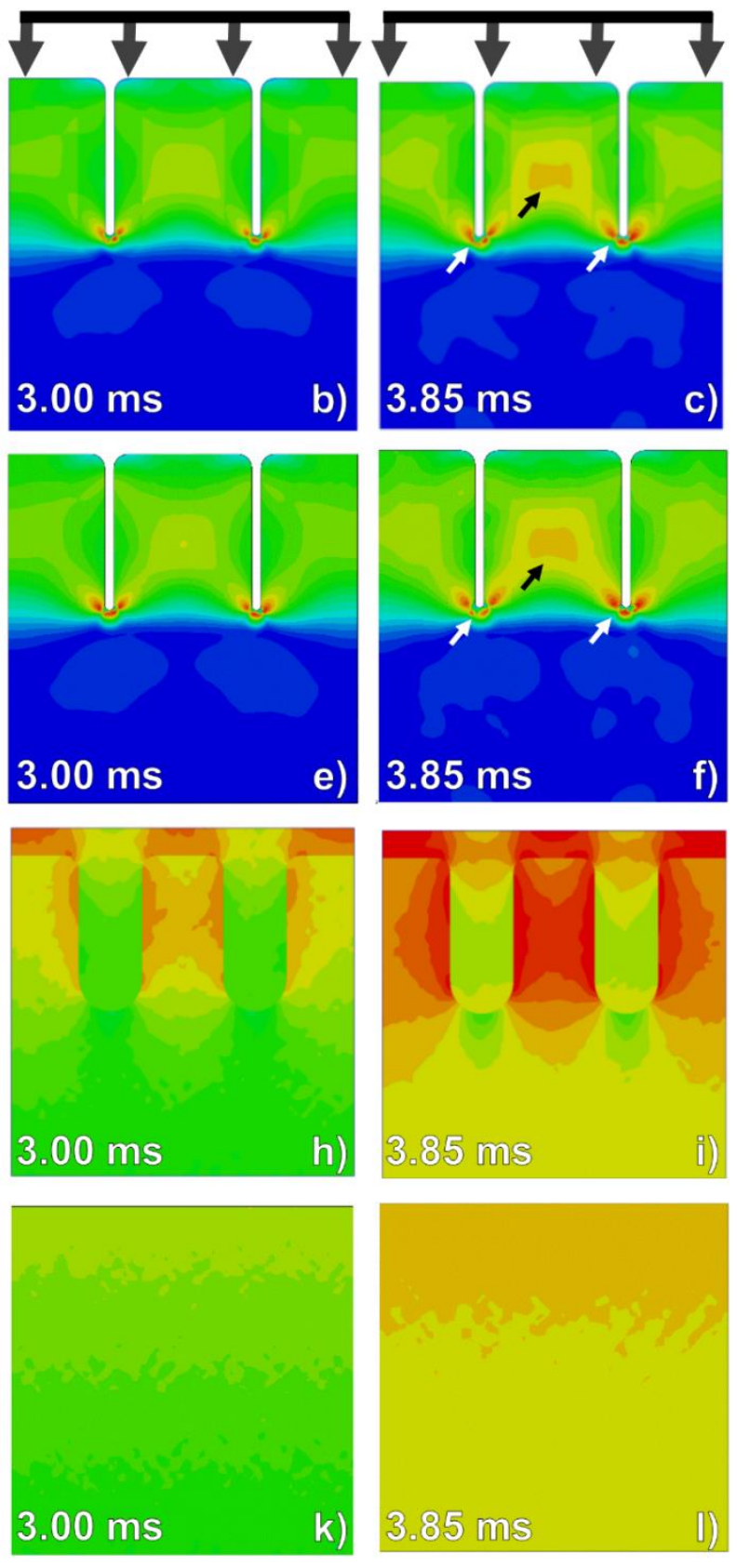

Figure 6. Von Mises stress (MPa) evolution in simulations with different geometry and structural compositions. All simulations were loaded from the top with the pressure-time histories observed in the frontal lobe during the football player head impact (Fig. 3), where the three columns, from left to right, present resulting von Mises stress contours at 2.25, 3.00, and $3.85 \mathrm{~ms}$, respectively. These models include (a) - (c) sulci and differentiated gray-white matter; (d) - (f) sulci and homogeneous brain; (g) - (i) differentiated gray-white matter without sulci; and (j) - (1) homogenous brain with no sulci. White and black arrows point to the location of the von Mises stress localizations arising from the near and far-field effects of sulci, respectively. The CSF and the infinite boundary are not shown for visual clarity. 

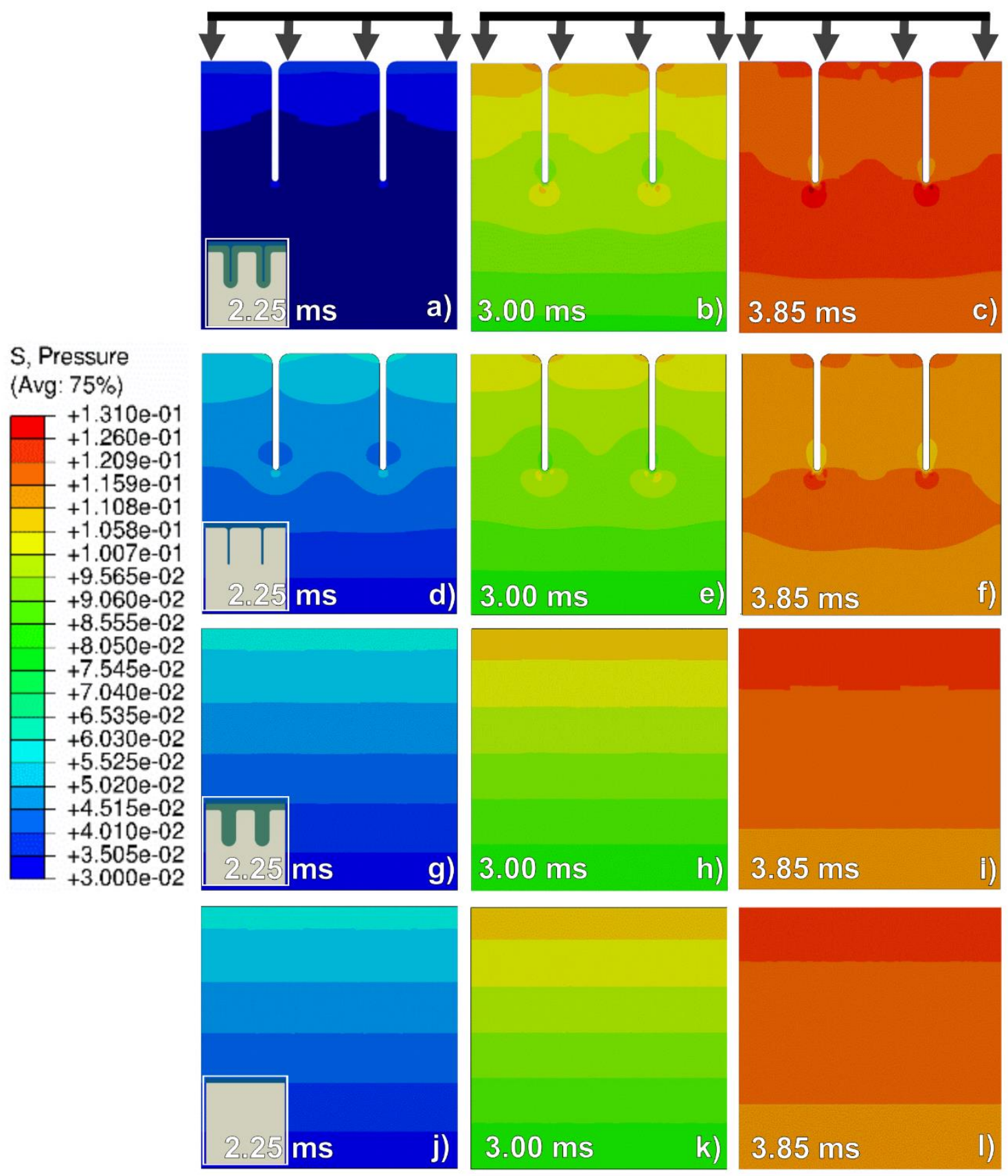

Figure 7. Pressure (MPa) evolution due to different structural complexities in mesoscale 2D finite element simulations. All simulations were loaded from the top with the pressure-time histories observed in the frontal lobe during the football player head impact (Fig. 3), where the three columns, from left to right, present resulting pressure contours at 2.25, 3.00, and $3.85 \mathrm{~ms}$, respectively. These models include (a) - (c) sulci and differentiated gray-white matter; (d) - (f) sulci and homogeneous brain; (g) - (i) differentiated gray-white matter with no sulci; and (j) - (l) homogenous brain with no sulci. The CSF and the infinite boundary are not shown for visual clarity. 


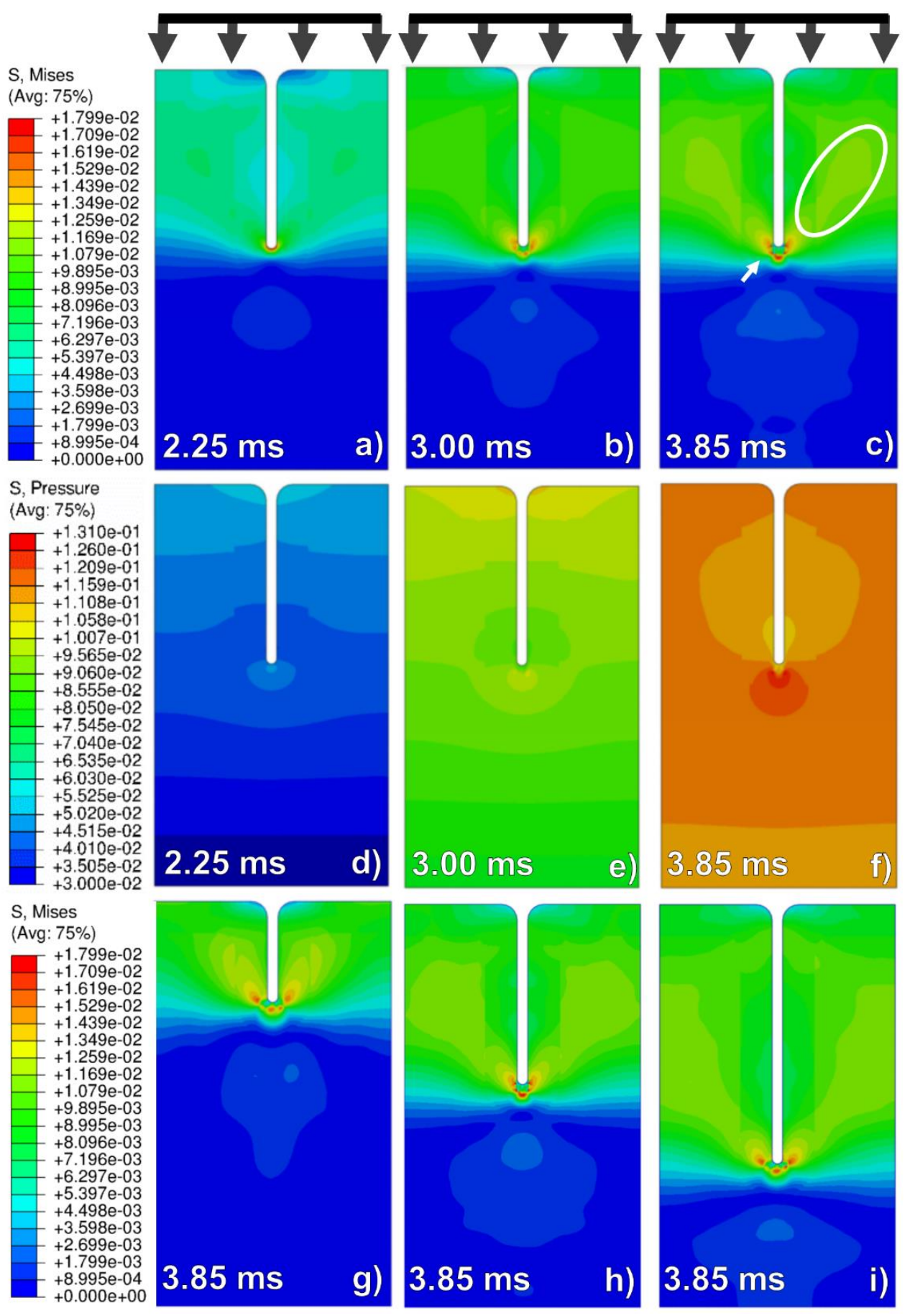

Figure 8. Mesoscale 2D finite element simulations of the frontal lobe with $14.5 \mathrm{~mm}$ sulcus during the frontal head impact of a football player simulation illustrating the time evolution of the von Mises stress (MPa) and pressure (MPa) contours at (a) and (d) $2.25 \mathrm{~ms}$, (b) and (e) $3.00 \mathrm{~ms}$, and (c) and (f) $3.85 \mathrm{~ms}$. The von Mises stress contours are then presented at peak applied pressure for different sulcus lengths: (g) $7.5 \mathrm{~mm}$, (h) $14.5 \mathrm{~mm}$, and (i) $24.5 \mathrm{~mm}$. The white arrow shows the von Mises stress localization arising from the inclusion of a sulcus with the von Mises stress band circled in white. The CSF and the infinite boundary are not shown for visual clarity. 
bioRxiv preprint doi: https://doi.org/10.1101/2020.06.09.141259; this version posted June 11, 2020. The copyright holder for this preprint (which was not certified by peer review) is the author/funder, who has granted bioRxiv a license to display the preprint in perpetuity. It is made available under aCC-BY-NC-ND 4.0 International license.
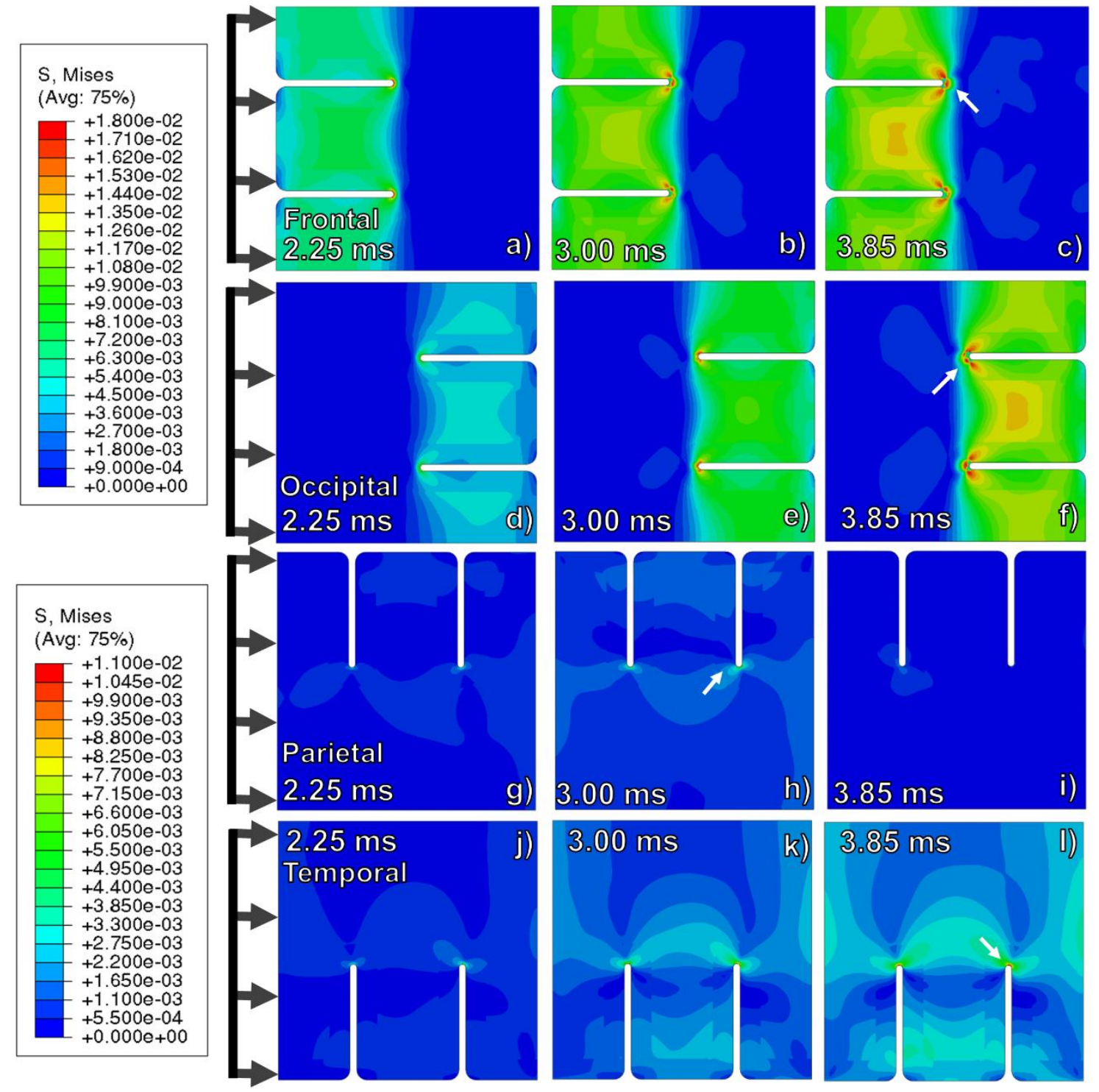

Figure 9. Mesoscale 2D finite element simulations of the four different brain lobes illustrating the von Mises stress $(\mathrm{MPa})$ evolution experienced during the frontal head impact of a helmeted football player. The three columns from left to right represent von Mises stress contours at 2.25, 3.00 , and $3.85 \mathrm{~ms}$, respectively. These simulations represent (a) - (c) the frontal lobe, (d) -(f) the occipital lobe, (g) - (i) the parietal lobe, and (j) - (l) the temporal lobe, with the white arrows showing the location of peak von Mises stress. The load is applied from the left side. The CSF and the infinite boundary are not shown for visual clarity. 
Table 4. Summarized average von Mises stress $\left(\bar{\sigma}_{v m}\right)$, maximum von Mises stress $\left(\sigma_{v m}^{\max }\right)$, maximum pressure $(\mathrm{P})$ observed in the mesoscale finite element simulations.

\begin{tabular}{|c|c|c|c|}
\hline & $\overline{\boldsymbol{\sigma}}_{v m}(\mathbf{k P a})$ & $\sigma_{v m}^{\max }(\mathbf{k P a})$ & $\mathbf{P}(\mathbf{k P a})$ \\
\hline \multicolumn{4}{|c|}{ Geometric and structural complexities in the frontal lobe (Figure 6 and Figure 7 ) } \\
\hline Differentiated brain, sulci, Pia matter & 5.578 & 18.06 & 126.3 \\
\hline Sulci, differentiated brain & 5.675 & 17.99 & 131.0 \\
\hline Differentiated brain & 0.457 & 0.585 & 122.7 \\
\hline Homogeneous brain, sulci & 5.792 & 17.72 & 127.0 \\
\hline Homogeneous brain & 0.433 & 0.455 & 122.5 \\
\hline \multicolumn{4}{|c|}{ Sulcus length (Figure 8) } \\
\hline $7.5 \mathrm{~mm}$ sulcus & 4.222 & 16.60 & 132.1 \\
\hline $15 \mathrm{~mm}$ sulcus & 5.410 & 17.80 & 130.9 \\
\hline $24.5 \mathrm{~mm}$ sulcus & 6.764 & 18.07 & 123.3 \\
\hline \multicolumn{4}{|c|}{ Different brain lobes (Figure 9 and Error! Reference source not found.) } \\
\hline Frontal & 5.675 & 17.99 & 131.0 \\
\hline Parietal & 0.969 & 6.26 & 11.29 \\
\hline Temporal & 2.224 & 11.08 & 23.83 \\
\hline Occipital & 5.730 & 18.05 & -126.0 \\
\hline \multicolumn{4}{|c|}{ Element size below the sulcus $($ Appendix D) } \\
\hline $0.1 \mathrm{~mm}^{*}$ & 5.675 & 17.99 & 131.0 \\
\hline All $0.25 \mathrm{~mm}$ & 5.361 & 17.53 & 127.9 \\
\hline All $0.5 \mathrm{~mm}$ & 5.691 & 17.68 & 127.3 \\
\hline All $1 \mathrm{~mm}$ & 5.719 & 17.05 & 126.5 \\
\hline All $2 \mathrm{~mm}$ & 6.373 & 15.94 & 126.5 \\
\hline
\end{tabular}

*localized mesh refinement below the sulcus 